\title{
Mate choice for major histocompatibility complex (MHC) complementarity in the Yellow-rumped Flycatcher (Ficedula zanthopygia)
}

Mingju $E^{1,2}$, Xiaolei Song ${ }^{2,3}$, Liufang Wang ${ }^{2,4}$, Yimo Yang ${ }^{2,5}$, Xianxiu Wei ${ }^{1}$, Jiangping Yu $^{2,4}$, Ye Gong ${ }^{2,4}$ and Haitao Wang ${ }^{2,4^{*}}$ (D)

\begin{abstract}
Background: Genes of the major histocompatibility complex (MHC) are an important component of the vertebrate immune system and play a significant role in mate choice in animal populations. However, the MHC genetic targets of female mate choice have not been clearly identified, and whether female mate choice is based on neutral genetic characteristics remains an open question. Here, we focus on the effects of morphological traits and genetic similarity among individuals in MHC class IIB (MHC IIB) exon 2 on mating in a sexually dimorphic songbird that exhibits social monogamy with extra-pair paternity (EPP).
\end{abstract}

Methods: We sequenced 64 parent-offspring triads sampled over a 3-year period using two MHC class II loci to detect disassortative mating in the Yellow-rumped Flycatcher (Ficedula zanthopygia).

Results: We found that MHC similarity in social pairs was lower than that in random pairs. Extra-pair mate choice according to MHC IIB was observed, in which females' extra-pair mates had fewer MHC alleles than their within-pair mates, but there was no significant band-sharing between extra-pair sires and potential extra-pair mates. However, the interaction between the MHC diversity of females and that of the social males affected the occurrence of EPP.

Conclusions: Our results support the "optimality hypothesis" of MHC-based social and extra-pair choice. Female choice probably maintains a certain level of MHC diversity in offspring in the Yellow-rumped Flycatcher.

Keywords: Extra-pair paternity, Mate choice, Optimality hypothesis, Yellow-rumped Flycatcher

\section{Background}

The prevalence and significance of precopulatory mate choice remains a keenly debated topic in sexual selection because of its potentially important influence on fitness, which is generally considered an adaptive evolutionary mechanism (Forstmeier et al. 2014).

\footnotetext{
*Correspondence: wanght402@nenu.edu.cn

2 Jilin Engineering Laboratory for Avian Ecology and Conservation

Genetics, School of Life Sciences, Northeast Normal University, Changchun 130024, China

Full list of author information is available at the end of the article
}

Mate choice is controversial mainly due to difficulties in quantifying the evolutionary costs and benefits of being "choosy" (Prokop et al. 2012; Forstmeier et al. 2014). Choosy females may obtain benefits derived from obtaining direct benefits (e.g., resources, territory or paternal care) (Griffin et al. 2013; Brouwer and Griffith 2019) and indirect benefits (e.g., genetic material) (Sheldon et al. 1997). Indirect benefits may not immediately contribute to the female's fitness but may benefit their progeny (genetic quality or compatibility). Paternity loss caused by extra-pair copulation

(C) The Author(s) 2021. This article is licensed under a Creative Commons Attribution 4.0 International License, which permits use, sharing, adaptation, distribution and reproduction in any medium or format, as long as you give appropriate credit to the original author(s) and the source, provide a link to the Creative Commons licence, and indicate if changes were made. The images or other third party material in this article are included in the article's Creative Commons licence, unless indicated otherwise in a credit line to the material. If material is not included in the article's Creative Commons licence and your intended use is not permitted by statutory regulation or exceeds the permitted use, you will need to obtain permission directly from the copyright holder. To view a copy of this licence, visit http://creativeco mmons.org/licenses/by/4.0/. The Creative Commons Public Domain Dedication waiver (http://creativecommons.org/publicdomain/ zero/1.0/) applies to the data made available in this article, unless otherwise stated in a credit line to the data. 
(EPC) is common among monogamous birds. EPCs are considered a way by which females could modify their initial mate choice (Brouwer and Griffith 2019). Several hypotheses have been proposed to explain the influence of male genetic quality on extra-pair mating, where quality is defined as the contribution of alleles or a genotype to individual fitness (Mays et al. 2008). According to genetic benefit hypotheses, females paired with high-quality males may be less prone to promiscuity, whereas those paired with poor-quality males may actively pursue EPCs to increase their offspring's fitness (Whittingham and Dunn 2010; Ferretti et al. 2011; Carlos and Botero 2012).

The major histocompatibility complex (MHC) contributes to the adaptive immune system and is a potential genetic marker of self-recognition versus non-self-recognition, pathogen-host interactions, and local adaptation (Eizaguirre et al. 2009; Spurgin et al. 2011). The MHC is regarded as an important candidate for mating preferences due to the potential genetic benefits that may be conferred to offspring (Penn and Potts 1998; Bos et al. 2009; Natsch et al. 2010). MHC-based mate-choice decisions have been reported across taxa, including mammals (Wang et al. 2010; Huchard et al. 2013; Ferrandiz-Rovira et al. 2016), birds (Juola and Dearborn 2012; Rymesova et al. 2017), reptiles (Olsson et al. 2003; Jaeger et al. 2016), amphibians (Bos et al. 2009) and fishes (Milinski et al. 2005; Agbali et al. 2010).

Theory suggests that females may gain indirect benefits, such as acquisition of "good" paternal genes (Hamilton and Zuk 1982) and enhanced survival of offspring, by choosing males with special or compatible genes (Brown 1997; Mays and Hill 2004). With respect to the MHC, females may choose among males to confer good paternal genes to their offspring, either by preferring "good" MHC haplotypes associated with enhanced resistance to pathogens or by avoiding "bad" MHC haplotypes associated with deleterious effects (Abplanalp et al. 1992; Wedekind et al. 1996). Alternatively, but not exclusively, females may seek the compatibility of maternal and paternal MHC genes to improve offspring MHC characteristics, either by choosing males with dissimilar MHC genes to maximize offspring MHC diversity (Brown 1997; E et al. 2017) or by choosing males with which they share an intermediate number of MHC alleles to optimize offspring MHC diversity at an intermediate level (Kloch et al. 2010; Hawley and Fleischer 2012). The optimality hypothesis is regarded as an extension of the genetic compatibility hypothesis (Han et al. 2019), which states that the optimal level of MHC diversity in offspring may be that conferring the most resistance against parasites and pathogens (Milinski et al. 2005; Cockburn et al. 2013).
In many socially monogamous species, individuals have been found to engage in extra-pair copulations (EPCs), which results in extra-pair paternity (EPP) (Westneat and Stewart 2003). EPP has been recorded in approximately $90 \%$ of investigated avian species (Griffith et al. 2002) and in other animal taxa. Social mate choice might be constrained by the need to acquire a dominant position before reproduction (Vaclav and Hoi 2007) and extrapair mate choice may be a way for females to adjust their mate choice and copulate with males possessing specific genetic characteristics (Gasparini et al. 2015). Extra-pair mating presents an opportunity to examine the processes governing mate choice in the absence of any potential direct benefits since the extra-pair male does not contribute to parental care (Dearborn et al. 2001). It is often predicted that females will choose extra-pair mates that are more ornamented than their social mates to gain superior genes for their offspring and, thus, indirect genetic benefits (Tschirren et al. 2012). Several studies have shown that MHC genes are important for mate choice, including extra-pair mate choice, in several passerine species, with females benefiting directly by mating with "healthy" males (e.g., being less likely to be infected with pathogens from their mates), but very few studies have addressed this question to date (Richardson et al. 2005; Santos et al. 2017; Rekdal et al. 2019). MHC genes thus provide an ideal study system to identify the specific functional loci effects of female mate choice (Penn and Potts 1998; Wedekind and Evanno 2010).

The Yellow-rumped Flycatcher (Ficedula zanthopygia) is a migratory, insectivorous, solitary-nesting species with biparental care (Alcaide et al. 2007; E et al. 2017), a high degree of sexual dimorphism in socially monogamous mating and moderate rates of EPP [with almost $50 \%$ of nests contain extra-pair young (EPY)] (E et al. 2017). According to microsatellite genotyping studies (E et al. 2017), female flycatchers are likely to choose males that are larger and relatively more heterozygous than their social mates as extra-pair mates. To assess MHC genotypes, we sequenced the second exon of the MHC class II B locus, which aids in the recognition of extracellular parasites and codes for the most polymorphic segment of the peptide-binding region in vertebrate genomes (Sallaberry et al. 2016). We predicted that the highly restrictive nature of social mate choice would prevent MHC-based social mate choice but would favour the evolution of MHC-based extra-pair mate choice. In this study, we compared the MHC genotypes of females with those of their social and extra-pair mates to determine whether within-pair or extra-pair matings were related to the overall MHC diversity of males or the compatibility of female and male genotypes. We specifically tested whether females mated preferentially with (1) more 
MHC-dissimilar mates, (2) more MHC-diverse males, or (3) males that provided an intermediate (optimal) level of MHC diversity for offspring. Finally, we investigated whether links were evident between the MHC II B genotype and phenotypic traits or body condition in the males preferred by females.

\section{Methods}

\section{Study population}

We studied a population of Yellow-rumped Flycatchers nesting at Zuojia Nature Reserve $\left(126^{\circ} 1^{\prime}-127^{\circ} 2^{\prime} \mathrm{N}, 44^{\circ} 6^{\prime}-\right.$ $45^{\circ} 5^{\prime}$ E) in Jilin Province, China. A detailed description of the study site and field procedures is given in $\mathrm{E}$ et al. (2017). The dataset included samples of 453 individuals (representing 64 nests and comprising 64 females, 64 males and 325 nestlings) collected during the breeding season in 2011-2013. The geographical position of each nest was recorded using a GPS device (N400PLUS, BHCnav, Beijing, China), and these data were used to calculate the linear distances between all breeding pairs in the study plot. To reduce the likelihood of nest abandonment as a result of early interference, a blood sample (approximately $20 \mu \mathrm{L}$ ) was collected from all adults and 6-7-dayold chicks and stored in absolute ethanol at $-20{ }^{\circ} \mathrm{C}$ until DNA extraction.

\section{MHC class Il genotyping}

Adult and nestling DNA was extracted from blood samples using a UNIQ-10 column animal genomic DNA isolation kit (SK1206, Sangon, Shanghai). To assess paternity, we genotyped all individuals at ten polymorphic microsatellite loci. The amplification conditions in this study are described in Leder et al. (2008); for more details on parentage analysis see E et al. (2017). We used the 326 and 325 degenerate primers (Ekblom et al. 2003) to perform partial amplification of exon 2. Using the resulting sequence, we designed a new primer pair (13-MHCNF: CTAA CGGC ACGG AGAA GG and 13-MHCNR: TCTG CGAT CCAC GCTG AA) that amplified a $240 \mathrm{bp}$ sequence comprising exon 2 , the region that contributes the most polymorphism to the peptide-binding site. For genotyping, we carried out denaturing gradient gel electrophoresis (DGGE) (Bonneaud et al. 2004). Each DGGE band was considered to correspond to one allele (Milinski et al. 2005). We grouped heterozygotes based on similarity in DGGE profile and then cloned one to three samples for each group using the PGEM-T Easy Vector System (Promega, Madison, WI, USA). All sequences were corrected, aligned and compared with those previously described for the same species (Wittzell et al.1999; Baratti et al. 2010).

\section{Statistical analyses}

We used CHROMAS version 2.01 (Technelesyum Pty Ltd, Brisbane, QLD, Australia) to correct the chromatograms. We translated the sequences, which had been previously aligned with CLUSTAL X version 1.83 , and calculated the proportion of amino acid differences between mates for each allele (p-distance) in MEGA v. 5.05 (Tamura et al. 2013). Then, we averaged those values for all the pairwise comparisons of alleles between individuals. Our estimates of MHC diversity included the total number of alleles in an individual. Allele sharing was calculated to estimate MHC similarity between males and females forming pair bonds. Allele sharing was estimated as twice the number of shared alleles divided by the number of different alleles of each individual, i.e., $D=2 F_{\mathrm{ab}} /\left(F_{\mathrm{a}}+F_{\mathrm{b}}\right)$ (Wetton et al. 1987). Allele sharing does not take into account the functional similarity of individuals, so we also obtained a second estimate based on amino acids. Body condition was evaluated using the residuals from a linear regression of body mass against tarsus length. Generalized linear mixed models (GLMMs) were used to assess the effect of allelic diversity (number of identified MHC class I alleles) of social fathers and mothers on the occurrence of EPP. Monitoring year and nest box ID were included as random factors to avoid pseudo replication by incorporating repeated measures, EPP was included as the dependent variable, and MHC band-sharing between the two social mates, clutch size, and the date of onset of laying were included as independent variables. The GLMMs were fitted using the "lme4" package of $\mathrm{R}$.

We examined the MHC diversity of these males and its similarity to that of females in four sets of comparisons. First, we used paired $t$ tests to compare the social mate with one or more nearby "unpaired" males that a female could have paired with but that were not chosen and apparently were less preferred $(n=44)$ (the 44 nests included in the analysis represented those cases where a nearest neighbour existed). These "unpaired" males did not have a mate at the time when the focal female settled, but most eventually gained a social mate. In those cases where multiple unpaired males were present (up to three), the values were averaged. Previous paternity analyses indicated that $95 \%$ of EPY are not sired by immediate neighbours (E et al. 2017). Second, we used independent-sample $t$ tests to compare MHC diversity and similarity between nests without EPY $(n=29$, representing the males that did not lose paternity) and without EPY ( $n=35$, containing at least one EPY), assuming that males with some EPY were less preferred than males without. Third, we used paired $t$ tests to examine MHC diversity and similarity for within-pair males and extrapair sires for the same nest. Last, we used paired $t$ tests 
to compare the MHC diversity and similarity of known extra-pair mates with those of potential extra-pair mates (neighbouring males).

To test whether partners were more dissimilar at the MHC locus than expected on the basis of random pairs, differences in MHC amino acid distance, functional distance and allele sharing between true pairs and randomly chosen pairs were analysed. Bootstrap confidence tests were performed with 10,000 permutations. We tested for correlation between phenotypic traits and the number of MHC alleles of the males, the occurrence of EPP and MHC band sharing between social mates using Spearman's correlation test. All statistical analyses were performed in R 3.5.3 (R Core Development Team, http:// cran.r-project.org/).

\section{Result}

\section{MHC variation}

The Yellow-rumped Flycatcher exhibited a high degree of MHC variability. At the population level, we recovered 15 unique class II sequences from 64 individuals, and individuals had $8.842 \pm 0.311$ (range: $4-15$ ) class II alleles. MHC band-sharing between females and males in the population was normally distributed around a mean of $0.628 \pm 0.140$ (Kolmogorov-Smirnov test: $Z=1.005$, $\mathrm{df}=63, p=0.265)$. Individual MHC diversity was not normally distributed $(\mathrm{mean}=5.671 \pm 1.661$; Kolmogorov-Smirnov test: $Z=1.416, \mathrm{df}=127, p=0.036$ ). Males and females in the population did not differ significantly in MHC diversity (Mann-Whitney test: $U=1510$, $\mathrm{df}=63, p=0.009$ ). Occurrence of EPP was negatively related to the MHC band sharing between social mates (Spearman's rho: $r=-0.377, n=35, p=0.025$ ) (Fig. 1).

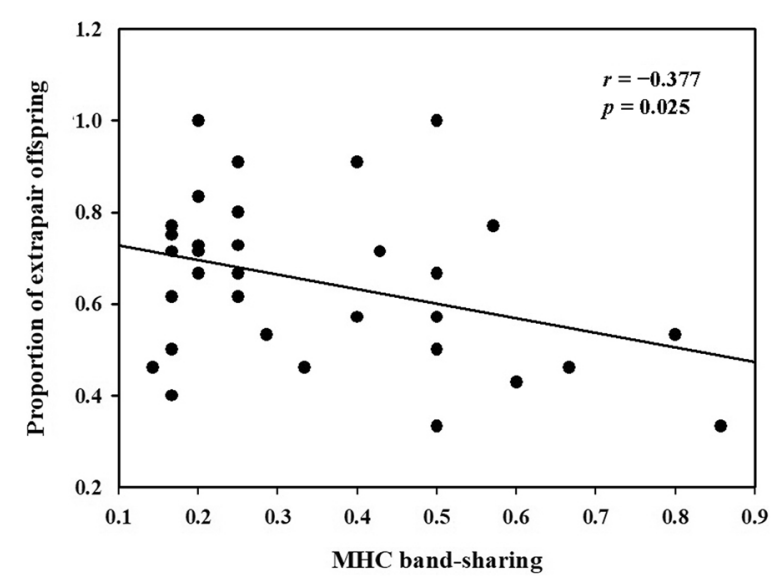

Fig. 1 Percentage of EPY in a brood in relation to the MHC class II amino MHC band-sharing between the female and her within-pair mate

\section{Social mate choice}

Compared with the social fathers, randomly assigned males did not have a greater number of MHC class II alleles that differed from those of the female. We found no significant difference in the mean or variance of amino acid distance of social mates from that of random dyads $(t=1.809, \mathrm{df}=63, p=0.075$; random: mean $=0.168$, social: mean $=0.165$ ) (Fig. 2). However, we found that social mates had higher band-sharing than random dyads $(t=-3.135, \mathrm{df}=63, p=0.003$; random: mean $=0.568$, social: mean $=0.638$ ) (Fig. 3 ). In addition, within-pair mates and unpaired males did not differ in the total number of class II alleles. However, with respect to relative similarity between females and their mates, compared with unpaired males, within-pair males shared more MHC alleles with the female (paired $t$ test: $t_{44}=3.111$, $p=0.003$ ) and exhibited lower amino acid distances from the female (paired $t$ test: $\left.t_{44}=2.076, p=0.044\right)$ (Table 1 ).

\section{EPP}

Compared with extra-pair mates, within-pair mates shared more MHC alleles with the females (paired $t$ test: $t_{34}=2.644, p=0.012$ ) and had significantly fewer amino acid differences from the females in their MHC alleles (paired $t$ test: $t_{34}=2.337, p=0.026$ ) (Table 2). However, there was no significant difference in MHC diversity between within-pair males and extra-pair males (paired $t$ test: $t_{34}=1.108, p=0.276$ ). Neither the female's MHC diversity (GLMM: $\chi^{2}=0.2381, \mathrm{df}=1$, $p=0.626$ ) nor the male's MHC diversity (GLMM: $\left.X^{2}=0.354, \mathrm{df}=1, p=0.552\right)$ significantly influenced the

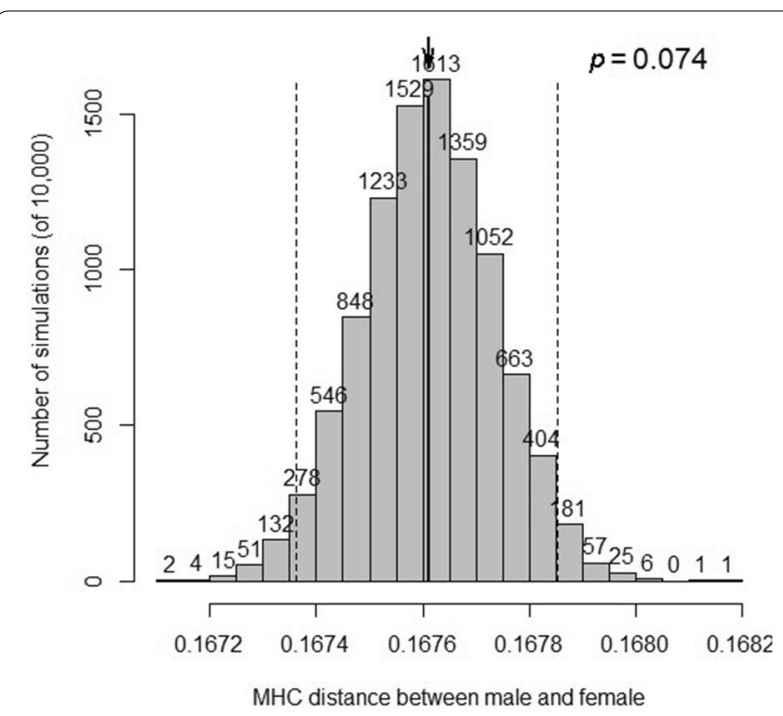

Fig. 2 Distribution of the 10,000 bootstrapped MHC distance values for pairs assembled at random from the whole male population (i.e., mated and non-mated males) 


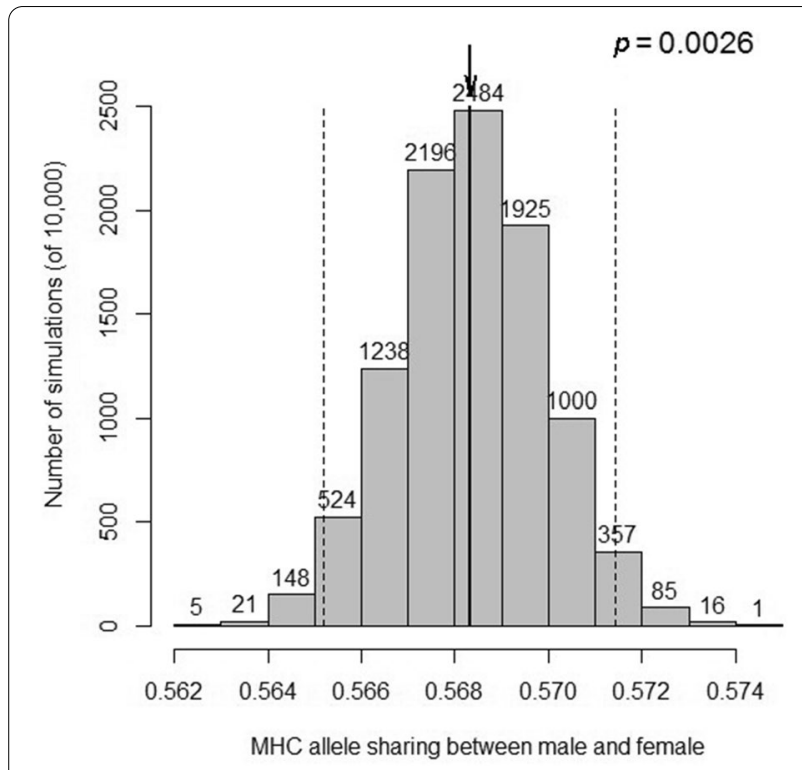

Fig. 3 Distribution of the 10,000 bootstrapped MHC band-sharing values for pairs assembled at random from the whole male population (i.e., mated and non-mated males)

occurrence of EPP. The interaction between the female's MHC diversity and the social male's MHC diversity had a significant effect on the occurrence of EPP (GLMM: $\chi^{2}=-0.337, \mathrm{df}=1, p=0.027$ ) (Table 3; Fig. 4).

\section{Correlates of MHC diversity}

Phenotypes that may be linked to male quality were then tested for a relationship with MHC diversity to determine whether they could be the direct cause of the link between extra-pair mate choice and MHC diversity. There was no correlation between MHC diversity and tarsal (Spearman's rho: $r=0.264, n=64, p=0.086$ ), bill (Spearman's rho: $r=0.223, n=64, p=0.076$ ), tail (Spearman's rho: $r=-0.036, n=64, p=0.777$ ), wing (Spearman's rho: $r=-0.002, n=64, p=0.377$ ) or body (Spearman's rho: $r=-0.010, \mathrm{n}=64, p=0.851$ ) lengths traits. The body condition index derived from the regression of weight against tarsal length was not related to the MHC diversity of the male (Spearman's rho: $r=0.037$, $n=64, p=0.771)$.

\section{Discussion}

In our study, we found evidence that female Yellowrumped Flycatchers tended to mate with males showing intermediate $\mathrm{MHC}$ diversity. It has been suggested that both natural and sexual selection may be driving the evolution of intermediate levels of diversity as a result of trade-offs between inbreeding and outbreeding depression (Bonneaud et al. 2006; Hansson and Westerberg 2008; Gagnon et al. 2020). In small populations, genetic diversity will be depleted if the majority of successful pairings have high pairwise similarities (leading to inbreeding), and will increase with dissimilar pairings

Table 1 Paired comparisons of MHC variation between within-pair males and nearest unpaired mates

\begin{tabular}{|c|c|c|c|c|c|}
\hline & $n$ & Within-pair mates & Unpaired mates & $t$ value & $p$ value \\
\hline $\begin{array}{l}\text { Male diversity } \\
\text { Total number of alleles }\end{array}$ & 44 & $6.159 \pm 0.184$ & $5.864 \pm 0.180$ & 1.067 & 0.292 \\
\hline $\begin{array}{l}\text { Similarity to the female } \\
\text { Proportion of alleles shared }\end{array}$ & 44 & $0.648 \pm 0.021$ & $0.5618 \pm 0.023$ & 3.111 & $0.003^{*}$ \\
\hline Amino acid distance & 44 & $0.115 \pm 0.0017$ & $0.126 \pm 0.0019$ & -2.076 & $0.044^{*}$ \\
\hline
\end{tabular}

Comparisons were made between within-pair mates and nearest unpaired mates (male diversity) and between the similarity estimates for the female and each type of male (similarity to the female). ${ }^{*}$ Significant with $p<0.05$

Table 2 Paired comparisons of MHC variation between within-pair and extra-pair mates

\begin{tabular}{|c|c|c|c|c|c|}
\hline & $n$ & Within-pair mates & Extra-pair sires & $t$ value & $p$ value \\
\hline $\begin{array}{l}\text { Male diversity } \\
\text { Total number of alleles }\end{array}$ & 34 & $6.206 \pm 0.197$ & $5.852 \pm 0.247$ & 1.108 & 0.276 \\
\hline $\begin{array}{l}\text { Similarity to the female } \\
\qquad D=2 F_{\mathrm{ab}} /\left(F_{\mathrm{a}}+F_{\mathrm{b}}\right)\end{array}$ & 34 & $0.626 \pm 0.023$ & $0.529 \pm 0.03$ & 2.644 & $0.012^{*}$ \\
\hline Amino acid distance & 34 & $0.163 \pm 0.002$ & $0.167 \pm 0.002$ & -2.337 & $0.026^{*}$ \\
\hline
\end{tabular}

Comparisons were made between within-pair and extra-pair mates (male diversity) and between the similarity estimates for the female and each type of male (similarity to the female). * Significant with $p<0.05$ 
Table 3 GLMMs models analysis showing the effect of MHC variation on EPP

\begin{tabular}{llcccc}
\hline Factors & df & $\boldsymbol{X}^{2}$ & Estimate & SE & $\boldsymbol{p}$ \\
\hline Female MHC diversity & 1 & 2.279 & 1.956 & 0.859 & $0.022^{*}$ \\
Social male MHC diversity & 1 & 0.416 & 0.634 & 1.523 & 0.678 \\
Female-social male MHC band-sharing & 1 & 2.209 & 1.905 & 0.863 & $0.028^{*}$ \\
Female MHC diversity* social male MHC diversity & 1 & -2.203 & -0.322 & 0.146 & $0.027^{*}$ \\
\hline
\end{tabular}

*Significant with $p<0.05$

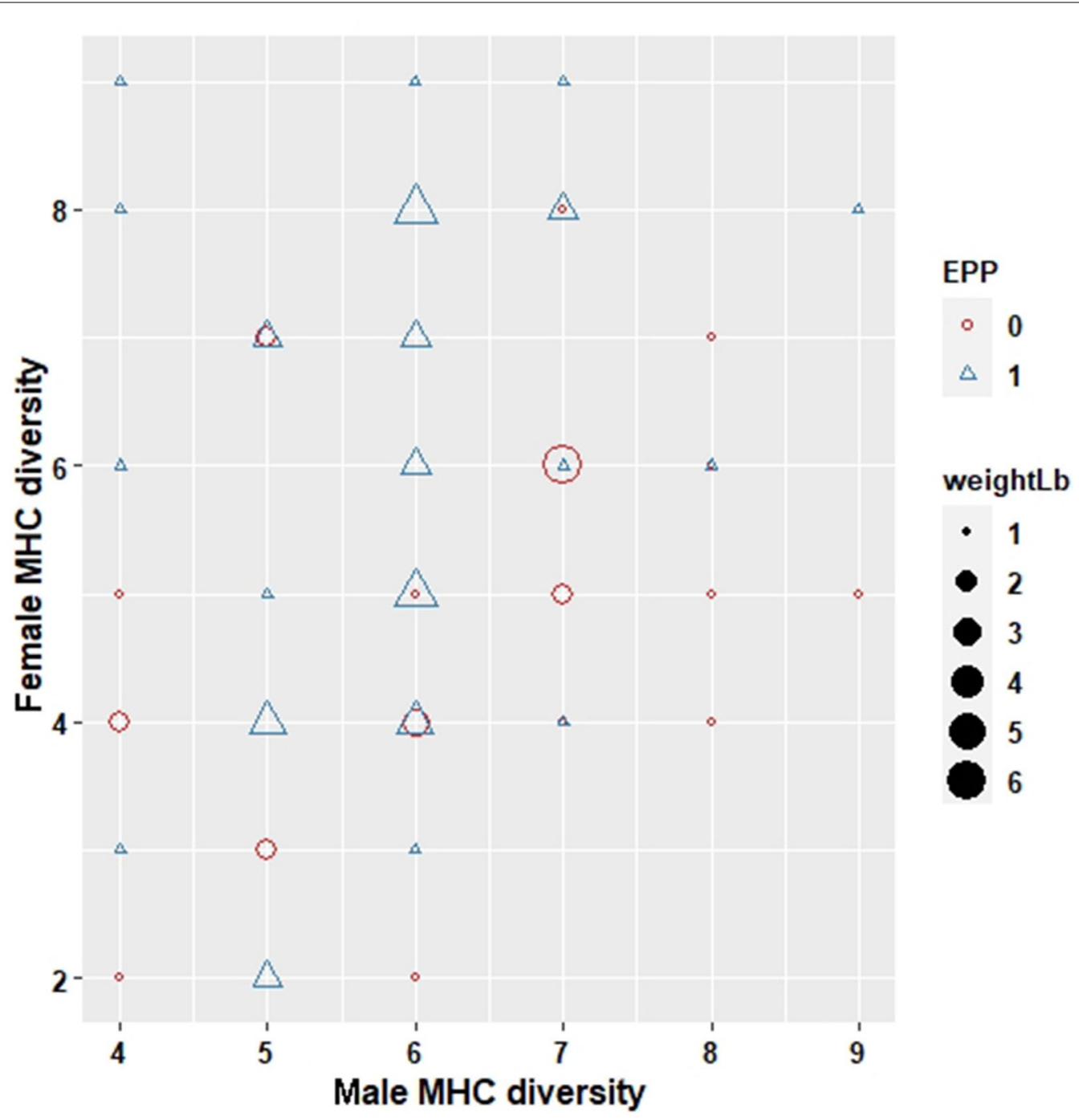

Fig. 4 The interaction between the female's MHC diversity and the social male's MHC diversity on the occurrence of EPP

as per the advantage asserted by the dissimilar mates' hypothesis (although outbreeding depression may be a potential risk; Chargé et al. 2014). We also compared the occurrence of EPP and MHC band sharing between social mates. We found a negative relationship of the incidence of EPP and the relatedness between social mates, which indicates the potential occurrence of outbreeding or some level of local mate competition (LMC), in this mating system (Aoki et al. 2007).

Several studies have found that it is possible for a population to maintain high levels of MHC diversity even in the face of extremely severe bottlenecks (i.e., in genetically depauperate populations) and/or under high inbreeding (Richardson et al. 2005; Ellison et al. 2011). 
In our study, neither the female's nor the male's MHC diversity significantly influenced the occurrence of EPP, but the interaction between the female's and that of the social male affected the occurrence of EPP. Furthermore, we found that extra-pair matings of females with males in their neighbourhoods did not depend on the MHC diversity of the males or their similarity to the female and that extra-pair mates showed MHC II diversity significantly different from that of the within-pair males they cuckolded. These results are consistent with mate choice for intermediate levels of MHC diversity. One explanation for these results is that females choose mates with an intermediate level of MHC diversity to avoid negative selection on $\mathrm{T}$ cell repertoire size and reduce the number of detectable pathogens (Wegner et al. 2003). After longdistance migration, Yellow-rumped Flycatchers may be in generally poorer condition than they were before migration and because of susceptibility to novel parasites in the new habitat, more infected and less fit (Stutz and Bolnick 2017). Another possibility is that females choose similar mates to avoid disruption of locally coadapted genes (Bonneaud et al. 2006; Eizaguirre et al. 2009), although this possibility awaits detailed study. However, we cannot exclude the possibility that male-male competition and cryptic female choice bias fertilization patterns (Andersson 1994; Jennions and Petrie 2000; Kamiya et al. 2014) and contributed to the observed pattern in our study.

Some studies have revealed correlations among MHC variation, external traits and mate choice. Females may assess the MHC genotypes of males by using phenotypic traits as cues. For example, in the endangered Crested Ibis (Nipponia nippon), mates are selected using UV visual capability (Sun et al. 2019). In the Common Pheasant (Phasianus colchicus), relationships between male phenotypic traits and certain MHC genotypes have been reported (Ekblom et al. 2003; Baratti et al. 2010; Hale et al. 2014; Yu et al. 2018). Thus, our study has some limitations. Although we found evidence that female Yellow-rumped Flycatchers prefer males with intermediate MHC II diversity, the phenotypic traits mediating the direct recognition of partners remain unknown and are difficult to observe. It is possible that such correlations could arise because both MHC and external traits are correlated with individual body condition, which is determined by other factors. In studies of mammal or fish taxa with well-developed olfaction, individuals are able to recognize both their own genotype and the genotype of potential partners, as observed in humans (Thornhill et al. 2003), mice (Firman and Simmons 2015), fish (Milinski et al. 2005; Gahr et al. 2018), and lizards (Olsson et al. 2003). However, most bird species are considered microsmatic or even anosmic (Roper 1999). Nevertheless, recent experimental work revealed MHC-dependent mate choice suggestive of an olfactory capability in Blue Petrels (Halobaena caerulea) (Strandh et al. 2012). Furthermore, Leclaire et al. (2017) showed that similarity in preen secretion chemicals is positively correlated with MHC relatedness in Black-legged Kittiwakes (Rissa tridactyla). The associations between the MHC, odours, and mating preferences in birds are a promising avenue for further exploration.

Associations between MHC genotype and social mate choice or extra-pair mate choice have been reported in a few species of vertebrates, and suggest a preference for the most heterozygous individuals or the use of MHC-based cues to evaluate the degree of relatedness of a potential partner to avoid inbreeding or outbreeding. However, the optimal level of genomic divergence for maximizing reproductive success be an intermediate level (Neff 2005; Slade et al. 2017). In this outbred population of Yellow-rumped Flycatchers, female choice probably maintains a certain level of diversity in the offspring while avoiding the costs of the disruption of local adaptations. We are aware that our sample size is modest in order to discovery of (dis-)assortative mating, although given the placement of our empirical mean in relation to the distribution generated by randomisations. Nevertheless, precise estimates (obtainable through the use of large sample sizes and/or very informative genetic markers) are required in further studies.

\section{Conclusion}

Our results support the optimality hypothesis and contribute to our knowledge of MHC-based social and extrapair choice in passerine birds. It appears that intermediate levels of MHC dissimilarity allow females to increase their inclusive fitness (Bichet et al. 2014) in the absence of significant inbreeding depression (Lehtonen and Kokko 2015; Sepil et al. 2015). However, our study gives rise to additional unsolved questions regarding MHC-mediated mate choice. For example, olfactory, colour or morphological traits are often found as reliable signals of the MHC profile, but our analysis shows that such traits, which might reflect male genetic quality were not correlated with male MHC diversity in the Yellow-rumped Flycatcher. Thus, MHC-mediated mate choice in this species may be determined by other factors, a possibility that warrants further study.

\section{Acknowledgements}

We thank Lin Wang, Can Sun, Jing Yue, and Junlong Yin for assistance in the field and the editors of American Journal Experts for help in refining the English language of the manuscript. 


\section{Authors' contributions}

HW conceived and designed the study. ME, XS, YG, and XW conducted the experiments in the field. ME, JY, YY and LW analysed the data and wrote the manuscript. All authors read and approved the final manuscript.

\section{Funding}

The study was financed by the National Natural Science Foundation of China (No. 31801976 to ME and No. 20111938 to HW), the University Student Innovation and Entrepreneurship Training Program of Jilin Province (No. 202010205057 to ME) and the Natural Science Foundation of Changchun Normal University.

\section{Declarations}

\section{Ethics approval and consent to participate}

The present study complies with the current laws of China. Fieldwork was carried out under the permission from the Zuojia Nature Reserve, Jilin, China. Experimental procedures were permitted by National Animal Research Authority in Northeast Normal University (Approval Number: NENU-20080416) and the Forestry Bureau of Jilin Province of China (Approval Number: [2006]178).

\section{Consent for publication}

Not applicable.

\section{Competing interests}

The authors declare that they have no competing interests.

\section{Author details}

${ }^{1}$ School of Life Sciences, Changchun Normal University, Changchun 130032, China. ${ }^{2}$ Jilin Engineering Laboratory for Avian Ecology and Conservation Genetics, School of Life Sciences, Northeast Normal University, Changchun 130024, China. ${ }^{3}$ Shenyang No.37 High School, Shenyang 110000, China. ${ }^{4} \mathrm{Jilin}$ Provincial Key Laboratory of Animal Resource Conservation and Utilization, School of Life Sciences, Northeast Normal University, Changchun 130024, China. ${ }^{5}$ Ministry of Education Key Laboratory of Vegetation Ecology, School of Life Sciences, Northeast Normal University, Changchun 130024, China.

\section{Received: 28 August 2020 Accepted: 12 May 2021}

Published online: 29 May 2021

\section{References}

Abplanalp H, Sato K, Napolitano D, Reid J. Reproductive performance of inbred congenic leghorns carrying different haplotypes for the major histocompatibility complex. Poultry Sci. 1992;71:9.

Agbali M, Reichard M, Bryjova A, Bryja J, Smith C. Mate choice for nonadditive genetic benefits correlate with $\mathrm{MHC}$ dissimilarity in the rose bitterling (Rhodeus ocellatus). Evolution. 2010;64:1683-96.

Alcaide M, Edwards SV, Negro JJ. Characterization, polymorphism, and evolution of MHC class II B genes in birds of prey. J Mol Evol. 2007;65:541-54.

Andersson MB. Sexual selection. Princeton: Princeton University Press; 1994.

Aoki S, Kurosu U, Buranapanichpan S. Female production within the gall and male production on leaves by individual alates of a social aphid. Insect Soc. 2007;54:356-62.

Baratti M, Ammannati M, Magnelli C, Massolo A, Dessì-Fulgheri F. Are large wattles related to particular $\mathrm{MHC}$ genotypes in the male pheasant? Genetica. 2010;138:657-65.

Bichet C, Penn DJ, Moodley Y, Dunoyer L, Cellier-Holzem E, Belvalette M, et al. Females tend to prefer genetically similar mates in an island population of house sparrows. BMC Evol Biol. 2014;14:47-58.

Bonneaud C, Sorci G, Morin V, Westerdahl H, Zoorob R, Wittzell H. Diversity of MHC class I and IIB genes in house sparrows (Passer domesticus). Immunogenetics. 2004;55:855-65.

Bonneaud C, Chastel O, Federici P, Westerdahl H, Sorci G. Complex MHC-based mate choice in a wild passerine. Proc Biol Sci. 2006;273:1111-6.

Bos D, Williams HRN, Gopurenko D, Bulut Z, Dewoody JA. Condition-dependent mate choice and a reproductive disadvantage for $\mathrm{MHC}$-divergent male tiger salamanders. Mol Ecol. 2009;18:3307-15.
Brouwer L, Griffith SC. Extra-pair paternity in birds. Mol Ecol. 2019;28:4864-82. Brown JL. A theory of mate choice based on heterozygosity. Behav Ecol. 1997;8:60-5.

Carlos A, Botero DR. Fluctuating environments, sexual selection and the evolution of flexible mate choice in birds. PLoS ONE. 2012;7:e32311.

Chargé R, Teplitsky C, Sorci G, Low M. Can sexual selection theory inform genetic management of captive populations? Evol Appl. 2014;7:1120-33.

Cockburn A, Brouwer L, Double MC, Margraf N, Martijn VDP. Evolutionary origins and persistence of infidelity in Malurus: the least faithful birds. Emu. 2013;113:208.

Dearborn DC, Anders AD, Parker PG. Sexual dimorphism, extrapair fertilizations, and operational sex ratio in great frigatebirds (Fregata minor). Behav Ecol. 2001;12:746-52

E MJ, Gong Y, Yu JP, Zhang SY, Fan QX, Jiang YL, Wang HT. Low level of extrapair paternity between nearest neighbors results from female preference for high-quality males in the Yellow-rumped Flycatcher (Ficedula zanthopygia). PLoS ONE. 2017;12:e0172713.

Eizaguirre C, Yeates SE, Lenz TL, Kalbe M, Milinski M. MHC-based mate choice combines good genes and maintenance of MHC polymorphism. Mol Ecol. 2009;18:3316-29.

Ekblom R, Grahn M, Hoglund J. Patterns of polymorphism in the MHC class Il of a non-passerine bird, the great snipe (Gallinago media). Immunogenetics. 2003;54:734-41.

Ellison A, Cable J, Consuegra S. Best of both worlds? Association between outcrossing and parasite loads in a selfing fish. Evolution. 2011;65:3021e3026.

Ferrandiz-Rovira M, Allaine D, Callait-Cardinal MP, Cohas A. Mate choice for neutral and $\mathrm{MHC}$ genetic characteristics in Alpine marmots: different targets in different contexts? Ecol Evol. 2016;6:4243-4257.

Ferretti V, Massoni V, Bulit F, Winkler DW, Lovette IJ. Heterozygosity and fitness benefits of extrapair mate choice in White-rumped swallows (Tachycineta leucorrhoa). Behav Ecol. 2011;22:1178-86.

Firman RC, Simmons LW. Gametic interactions promote inbreeding avoidance in house mice. Ecol Lett. 2015;18:937-43.

Forstmeier W, Nakagawa S, Griffith SC, Kempenaers B. Female extrapair mating: adaptation or genetic constraint? Trends Ecol Evol. 2014;29:456-64.

Gagnon M, Yannic G, Boyer F, Steeve D. Adult survival in migratory caribou is negatively associated with MHC functional diversity. Heredity. 2020;125:1-14

Gahr CL, Boehm T, Milinski M. Female assortative mate choice functionally validates synthesized male odours of evolving stickleback river-lake ecotypes. Biol Lett. 2018;14:20180730.

Gasparini C, Congiu L, Pilastro A. Major histocompatibility complex similarity and sexual selection: different does not always mean attractive. Mol Ecol. 2015:24:4286-95.

Griffin AS, Alonzo SH, Cornwallis CK. Why do cuckolded males provide paternal care? PLoS Biol. 2013;11:e1001520.

Griffith SC, Owens IPF, Thuman KA. Extra pair paternity in birds: a review of interspecific variation and adaptive function. Mol Ecol. 2002;11:2195-212.

Hale JA, Nelson DA, Augustine JK. Are vocal signals used to recognize individuals during male-male competition in greater prairie-chickens (Tympanuchus cupido)? Behav Ecol Sociobiol. 2014;68:1441-9.

Hamilton WD, Zuk M. Heritable true fitness and bright birds: a role for parasites? Science. 1982;218:384-7.

Han QH, Sun RN, Yang HQ, Wang ZW, Wan QH, Fang SG. MHC class I diversity predicts non-random mating in Chinese alligators (Alligator sinensis). Heredity. 2019;12:809-18.

Hansson B, Westerberg L. Heterozygosity-fitness correlations within inbreeding classes: local or genome-wide effects? Conserv Genet. 2008;9:73-83.

Hawley DM, Fleischer RC. Contrasting epidemic histories reveal pathogenmediated balancing selection on Class II MHC diversity in a wild songbird. PLOS ONE. 2012;7:e30222.

Huchard E, Baniel A, Schliehe S, Kappeler PM. MHC-disassortative mate choice and inbreeding avoidance in a solitary primate. Mol Ecol. 2013;22:4071-86.

Jaeger CP, Duvall MR, Swanson BJ, Phillips CA, Dreslik MJ, Baker SJ, et al. Microsatellite and major histocompatibility complex variation in an endangered rattlesnake, the Eastern Massasauga (Sistrurus catenatus). Ecol Evol. 2016;6:3991-4003. 
Jennions MD, Petrie M. Why do females mate multiply? A review of the genetic benefits. Biol Rev. 2000;75:21-64.

Juola FA, Dearborn DC. Sequence-based evidence for major histocompatibility complex-disassortative mating in a colonial seabird. Proc Biol Sci. 2012;279:153-62.

Kamiya T, O'D wyer K, Westerdahl H, Senior A, Nakaga S. A quantitative review of MHC-based mating preference: the role of diversity and dissimilarity. Mol Ecol. 2014;23:5151-63.

Kloch A, BabikW, Bajer A, Siński E, Radwan J. Effects of an MHC-DRB genotype and allele number on the load of gut parasites in the bank vole Myodes glareolus. Mol Ecol. 2010;19:255-65.

Leclaire S, Strandh M, Mardon J, Westerdahl H, Bonadonna F. Odour-based discrimination of similarity at the major histocompatibility complex in birds. Proc Biol Sci. 2017:284:20162466.

Leder E, Karaiskou N, Primmer C. Seventy new microsatellites for the pied Flycatcher, Ficedula hypoleuca and amplification in other passerine birds. Mol Ecol. 2008:8:874-80

Lehtonen J, Kokko H. Why inclusive fitness can make it adaptive to produce less fit extra-pair offspring. P Royal Soc B. 2015;282:20142716.

Mays H, Hill G. Choosing mates: good genes versus genes that are a good fit. Trends Evol. 2004;19:554-9.

Mays HL Jr, Albrecht T, Liu M, Hill GE. Female choice for genetic complementarity in birds: a review. Genetica. 2008;134:147-58.

Milinski M, Griffiths S, Wegner KM, Reusch TB, Haas-Assenbaum A, Boehm T. Mate choice decisions of stickleback females predictably modified by MHC peptide ligands. Proc Natl Acad Sci USA. 2005;102:4414-8.

Natsch A, Kuhn F, Tiercy J. Lack of evidence for HLA-linked patterns of odorous carboxylic acids released from glutamine conjugates secreted in the human axilla. J Chem Ecol. 2010;36:837-46.

Neff BD. Genetic quality and sexual selection: an integrated framework for good genes and compatible genes. Mol Ecol. 2005:14:19.

Olsson M, Madsen T, Nordby J, Wapstra E, Ujvari B, Wittsell H. Major histocompatibility complex and mate choice in sand lizards. P Roy Soc B-Biol Sci. 2003;270:S254-6.

Penn D, Potts W. MHC-disassortative mating preferences reversed by crossfostering. Proc Biol Sci. 1998;265:1299-306.

Prokop ZM, Michalczyk L, Drobniak SM, Herdegen M, Radwan J. Meta-analysis suggests choosy females get sexy sons more than "good genes." Evolution. 2012;66:2665-73.

Promerová M, Vinkler M, Bryja J, Poláková R, Schnitzer J, Munclinger P, et al. Occurrence of extra-pair paternity is connected to social male's MHCvariability in the scarlet rosefinch Carpodacus erythrinus. J Avian Biol. 2011:42:5-10.

Rekdal S, Anmarkrud J, Lifjeld J, Johnsen A. Extra-pair mating in a passerine bird with highly duplicated major histocompatibility complex class II: preference for the golden mean. Mol Ecol. 2019;28:5133-44.

Richardson DS, Komdeur J, Burke T, Schantz T. MHC-based patterns of social and extra-pair mate choice in the Seychelles warbler. Proc Biol Sci. 2005:272:759-67.

Roper TJ. Olfaction in birds. Adv Stud Behav. 1999;28:247-332.

Rymesova D, Kralova T, Promerova M, Bryja J, Tomasek O, Svobodova J, et al, Mate choice for major histocompatibility complex complementarity in a strictly monogamous bird, the grey partridge (Perdix perdix). Front Zool. 2017;14:9.

Sallaberry N, Gonzalez D, Padilla P. Dantas GPM, Luna-Jorquera G, Frere E, et al. Contrasting patterns of selection between $\mathrm{MHC}$ I and II across populations of Humboldt and Magellanic penguins. Ecol Evol. 2016;6:7498-510.

Santos P, Michler F, Sommer S. Can MHC-assortative partner choice promote offspring diversity? A new combination of MHC-dependent behaviours among sexes in a highly successful invasive mammal. Mol Ecol. 2017;26:2392-404.

Sepil I, Radersma R, Santure AW, De Cauwer I, Slate J, Sheldon BC. No evidence for MHC class I-based disassortative mating in a wild population of great tits. J Evol Biol. 2015:28:642-54.
Sheldon BC, Merilä J, Qvarnström A, Gustafsson L, Ellegren H. Paternal genetic contribution to offspring condition predicted by size of male secondary sexual character. P Lond Math Soc. 1997:264:297-302.

Slade JWG, Watson MJ, MacDougall-Shackleton EA. Birdsong signals individual diversity at the major histocompatibility complex. Biol Lett. 2017;13:20170430.

Spurgin LG, van Oosterhout C, Illera JC, Bridgett S, Gharbi K, Emerson BC, et al. Gene conversion rapidly generates major histocompatibility complex diversity in recently founded bird populations. Mol Ecol. 2011:20:5213-25.

Strandh M, Westerdahl H, Pontarp M, Canback B, Dubois MP, Miquel C, et al. Major histocompatibility complex class II compatibility, but not class I, predicts mate choice in a bird with highly developed olfaction. Proc Biol Sci. 2012;279:4457-63.

Stutz WE, Bolnick DI. Natural selection on MHC II beta in parapatric lake and stream stickleback: balancing, divergent, both or neither? Mol Ecol. 2017:26:4772-86.

Sun L, Zhou T, Stone GN, Wan QH, Fang SG. Seeing-good-gene-based mate choice: from genes to behavioural preferences. J Anim Ecol. 2019;88:1708-19.

Tamura K, Stecher G, Peterson D, Filipski A, Kumar S. MEGA6: molecular evolutionary genetics analysis version 6.0. Mol Biol Evol. 2013;30:2725.

Thornhill R, Gangestad SW, Miller RD, Scheyd G, Mccollough JK, Franklin M. Major histocompatibility complex genes, symmetry, and body scent attractiveness in men and women. Behav Ecol. 2003;14:668-78.

Tschirren B, Postma E, Rutstein AN, Griffith SC. When mothers make sons sexy: maternal effects contribute to the increased sexual attractiveness of extra-pair offspring. Proc Biol Sci. 2012;279:1233-40.

Vaclav R, Hoi H. Experimental manipulation of timing of breeding suggests laying order instead of breeding synchrony affects extra-pair paternity in house sparrows. J Ornithol. 2007;148:395-400.

Wang N, Li J, Liu Y, Zhang Z. Improvement on molecular sex identification primers for Passeriform bird species. Avian Res. 2010;1:65-9.

Wedekind C, Evanno G. Mate choice, the major histocompatibility complex, and offspring viability. In: Human evolutionary biology. Cambridge: Cambridge University Press; 2010. p. 309-21.

Wedekind C, Chapuisat M, Macas E, Rulicke T. Non-random fertilization in mice correlates with the MHC and something else. Heredity. 1996;77:400-9.

Wegner KM, Reusch TB, Kalbe M. Multiple parasites are driving major histocompatibility complex polymorphism in the wild. J Evol Biol. 2003:16:224-32.

Westneat DF, Stewart IRK. Extra-pair paternity in birds: causes, correlates, and conflict. Annu Rev Ecol Evol S. 2003:34:365-96.

Wetton CJHRE, Parkin DT, Walters D. Demographic study of a wild house sparrow population by DNA fingerprinting. Nature. 1987;327:147-9.

Whittingham LA, Dunn PO. Fitness benefits of polyandry for experienced females. Mol Ecol. 2010;19:2328-35.

Wittzell H, Bernot C, Auffray Zoorob R. Concerted evolution of two MHC class II B loci in pheasants and domestic chickens. Mol Biol Evol. 1999;16:479-90.

Yu L, Nie Y, Yan L, Hu Y, Wei F. No evidence for MHC-based mate choice in wild giant pandas. Ecol Evol. 2018;8:8642-51.

Ready to submit your research? Choose BMC and benefit from:

- fast, convenient online submission

- thorough peer review by experienced researchers in your field

- rapid publication on acceptance

- support for research data, including large and complex data types

- gold Open Access which fosters wider collaboration and increased citations

- maximum visibility for your research: over 100M website views per year

At BMC, research is always in progress.

Learn more biomedcentral.com/submissions 